\title{
Influence of Particle Size Distribution of High Calcium Fly Ash on HVFA Mortar Properties
}

\author{
Antoni1 ${ }^{1, *}$, Wibawa, H.S. ${ }^{2}$, and Hardjito, D. ${ }^{1}$
}

\begin{abstract}
This study evaluates the effect of particle size distribution (PSD) of high calcium fly ash on high volume fly ash (HVFA) mortar characteristics. Four PSD variations of high calcium fly ash used were: unclassified fly ash and fly ash passing sieve No. 200, No. 325 and No. 400, respectively. The fly ash replacement ratio of the cementitious material ranged between $50-70 \%$. The results show that with smaller fly ash particles size and higher levels of fly ash replacement, the workability of the mixture was increased with longer setting time. There was an increase in mortar compressive strength with finer fly ash particle size, compared to those with unclassified ones, with the highest strength was found at those with fly ash passing mesh No. 325. The increase was found due to better compactability of the mixture. Higher fly ash replacement reduced the mortar's compressive strength, however, the rate was reduced when finer fly ash particles was used.
\end{abstract}

Keywords: Fly ash; high calcium; particle size distribution; superplasticizer demand; setting time; HVFA.

\section{Introduction}

High volume fly ash (HVFA) concrete has fly ash content more than $50 \%$ of the cementitious material. Malhotra and Mehta [1] proposed the definition of HVFA concrete based on the possibility of making high performance concrete using higher volume of good quality fly ash as cement replacement. Fly ash, with its spherical shape, reduces the water requirement for a more workable mixture, and increases the compressive strength of concrete with its pozzolanic reaction and very fine particle size. HVFA concrete was shown to have better performance compared to low volume fly ash concrete, given the mixture was sufficiently controlled with low water to cementitious ratio and the use of admixture [2-4].

Both high calcium (type C) and low calcium (type F) fly ash have been studied for making HVFA concrete with satisfactory results. However, using high calcium fly ash, which may undergo both hydration and pozzolanic reaction, compared to low calcium fly ash with only pozzolanic reaction, is an added advantage in increasing concrete's long term strength development.

\section{${ }^{1}$ Civil Engineering Department, Petra Christian University, Sura- baya, INDONESIA \\ ${ }^{2}$ Masters Program in Civil Engineering, Petra Christian Univer- sity, Surabaya, INDONESIA \\ * Corresponding author: antoni@petra.ac.id}

Note: Discussion is expected before November, $1^{\text {st }} 2018$, and will be published in the "Civil Engineering Dimension", volume 21, number 1, March 2019

Received 03 August 2018; revised 03 September 2018; accepted 09 September 2018.
Fly ash has varying qualities, depending on the burning process and the coal source. This may lead to more uncertainty in producing high quality HVFA concrete. Methods to improve the quality of fly ash had been introduced previously [5], however the variation is still big enough to produce a good and consistent HVFA concrete, and thus low quality fly ash is not recommended for making HVFA concrete. The consistency of the fly ash quality has been studied by the authors [6], and it was found that when the variation of the fly ash can be controlled, then a good quality HVFA concrete can be produced. The influence of particle size or particle size distribution of the cementitious materials has been studied by several authors [7-10]. Finer cementitious material improves the particle packing of concrete, and thus increases its strength and durability. Some of the studies were performed at lower fly ash replacement ratio, showing that finer fly ash improves the workability and cohesion of concrete mixture, and also the packing density of concrete.

Methods to obtain finer fly ash particle size or particle size distribution vary from one to the other researchers. Some sieve the coarser particles into ranges of finer ones [4], while the other blend the finer and coarser particles to obtain the desired particle size distribution [11]. These two methods may limit the application, especially in large volume. Grinding fly ash causes irregular shape and rough surface of the particles, and thus reduces the workability. On the other hand, blending several sizes to obtain desired particle size distribution may not be practical for large volume application to 
produce HVFA concrete.

The aim of this study is to maximize the use of high calcium fly ash to produce high strength HVFA mortar. Fly ash properties were improved by altering its particle size distribution by means of sieving fly ash particles through a particular sieve size, without any lower bound size limit. In practice, this method can be applied by using air separator with controlled wind speed. The HVFA mortar contains 50\% to $70 \%$ fly ash replacing cement content in the mixture with four different particle size distributions. The fresh and hardened mortar properties were examined.

\section{Materials and Methods}

The high calcium fly ash was obtained from a pulverized coal combustion power plant in Paiton, East Java, Indonesia. The fly ash from this power plant has been studied extensively and it was found to have good consistent quality [6]. The fly ash was then classified as original without sieving and those passing sieve No. $200(75 \mu \mathrm{m})$, sieve No. $325(45 \mu \mathrm{m})$, and sieve No. $400(38 \mu \mathrm{m})$, respectively, under dry condition. For large scale operation, particle size separation using air separator to reduce the maximum particle size is more practical. On the other hand, blending fine and coarse particles to obtain target size distribution [11] could be impractical in large scale construction practice. Classification of fly ash particles should avoid grinding to preserve the spherical shape of the particles. HVFA mortar mixture was evaluated by replacing fly ash at $50 \%$, $60 \%$, and $70 \%$ of the cementitious material, by mass. The cement used was Portland Pozzolan cement from local cement manufacturer. The sand used was obtained from Lumajang Quarry, East Java, Indonesia, with a specific gravity of 2.7 , and conditioned to conform to the standard gradation of ASTM C778-13 [12]. The admixture used was superplasticizer Viscocrete 1003, a polycarboxylate based admixture from SIKA.

One of the advantages of using higher volume of fly ash in concrete mixture is that the water to cementitious ratio can be greatly reduced due to the spherical shape of the fly ash that can act as a ball bearing in the mixture, improving the workability of the concrete mixture. Hence, the water to cementitious ratio of the mortar mixtures used in this study was fixed at 0.25 . Sand to cementitious material ratio was also fixed at 2 , by mass. The addition of superplasticizer to achieve the target workability of $15 \pm 1 \mathrm{~cm}$, after 25 drops on the flow table test [13], was carried out by spraying it gradually into the mortar mixture. The superplasticizer dosage added is defined as the superplasticizer demand to achieve the target workability of fresh mortar with constant water to cementitious ratio. Controlling both worka- bility and water to cementitious ratio using superplasticizer was crucial to produce comparable fresh and hardened properties of the blended cementitious material mixture.

The fresh mortar was mixed using a hand drill in a bucket, and cast into $5 \times 5 \times 5 \mathrm{~cm}$ cube molds. One day after casting, the specimens was demolded and cured under water until one day before the compressive strength test. Compressive strength test was done at the age of 7 and 28 days, on three specimens for each variable and testing day. Setting time was measured on the fresh HVFA paste by using Vicat needle. The mixture composition of the cementitious paste for setting time test was the same as the paste of mortar mixture.

\section{Results and Discussions}

\section{Fly Ash Materials}

The chemical composition of the fly ash measured by $\mathrm{X}$-ray fluorescence (XRF) is shown in Table 1. The fly ash from Paiton power plant used in this research can be classified as high calcium fly ash or fly ash type $\mathrm{C}$ with $\mathrm{SiO}_{2}+\mathrm{Al}_{2} \mathrm{O}_{3}+\mathrm{Fe}_{2} \mathrm{O}_{3}$ content of $64.69 \%$ and $\mathrm{CaO}$ content of $19.52 \%$. Loss on ignition (LOI) of the fly ash is found to be very low at $0.26 \%$, showing that the combustion process in the power plant is quite efficient and the fly ash could be used to produce high quality concrete.

Table 1. The Chemical Composition of Fly Ash used in the Study

\begin{tabular}{lrll}
\hline Oxide & \multicolumn{1}{c}{$\%$} & Oxide & \% \\
\hline $\mathrm{SiO}_{2}$ & 31.24 & $\mathrm{~K}_{2} \mathrm{O}$ & 0.88 \\
$\mathrm{Al}_{2} \mathrm{O}_{3}$ & 15.92 & $\mathrm{Na}_{2} \mathrm{O}$ & 2.85 \\
$\mathrm{Fe}_{2} \mathrm{O}_{3}$ & 17.53 & $\mathrm{SO}_{3}$ & 1.72 \\
$\mathrm{TiO}_{2}$ & 0.65 & $\mathrm{MnO}_{2}$ & 0.21 \\
$\mathrm{CaO}$ & 19.52 & $\mathrm{P}_{2} \mathrm{O}_{5}$ & 0.26 \\
$\mathrm{MgO}$ & 8.41 & $\mathrm{~L} \mathrm{O} \mathrm{I}$ & 0.26 \\
$\mathrm{SiO}_{2}+\mathrm{Al}_{2} \mathrm{O}_{3}+\mathrm{Fe}_{2} \mathrm{O}_{3}$ & & & 64.69 \\
\hline
\end{tabular}

The specific gravity (GS) and summary of particle size analysis (PSA) of each material used are shown in Table 2. From the GS values, it can be seen that the finer size of fly ash particles has the higher specific gravity. The FA400, i.e. fly ash passing sieve No.400, has GS value of $3.057 \mathrm{ton} / \mathrm{m}^{3}$, similar to the one of Portland Pozzolan cement. Higher GS value indicates that the finer fly ash particles have more solid material in a unit volume.

Particle size analysis (PSA) was conducted on all cementitious materials that were used in the study. The results are shown in Figure 1 for each of the cementitious material. It was shown that cement having a quite uniform size with median size at about $25 \mu \mathrm{m}$. The unclassified fly ash already having 
smaller particle size than the cement, showing that it could improve the packing density of the concrete mixture. Classification by sieving reduces the maximum particle size as measured in $\mathrm{d}(90)$ values. FA200, FA325, and FA400 had $90 \%$ of the particle size finer than $30.5 \mu \mathrm{m}, 23.7 \mu \mathrm{m}$, and $19 \mu \mathrm{m}$, respectively, while the smallest particle diameter remains similar.

Specific surface area (SSA) was calculated for each fly ash sample. Table 2 also shows that the SSA value of fly ash sample with finer maximum particle size is increased. The SSA of FA400 has the largest value of $1018 \mathrm{~m}^{2} / \mathrm{kg}$, about 2.5 times the SSA of the cement, while the SSA of FA325 is about twice of the SSA of the cement.

Table 2. The Specific Gravity of Materials and the Results of Particle Size Analysis

\begin{tabular}{lccccc}
\hline Materials & $\begin{array}{c}\text { Specific } \\
\text { Gravity } \\
\left(\text { ton } / \mathrm{m}^{3}\right)\end{array}$ & $\begin{array}{r}\mathrm{d}(10) \\
(\mu \mathrm{m})\end{array}$ & $\begin{array}{r}\mathrm{d}(50) \\
(\mu \mathrm{m})\end{array}$ & $\begin{array}{r}\mathrm{d}(90) \\
(\mu \mathrm{m})\end{array}$ & $\begin{array}{c}\text { Specific } \\
\text { Surface Area } \\
\left(\mathrm{m}^{2} / \mathrm{kg}\right)\end{array}$ \\
\hline Cement & 3.140 & 2.13 & 24.28 & 49.50 & 410.35 \\
FA & 2.656 & 0.70 & 9.25 & 43.72 & 480.31 \\
\hline FA200 & 2.833 & 0.60 & 7.26 & 30.50 & 681.28 \\
FA325 & 3.003 & 0.52 & 4.71 & 23.74 & 818.72 \\
FA400 & 3.057 & 0.65 & 4.39 & 19.02 & 1018.89 \\
\hline
\end{tabular}

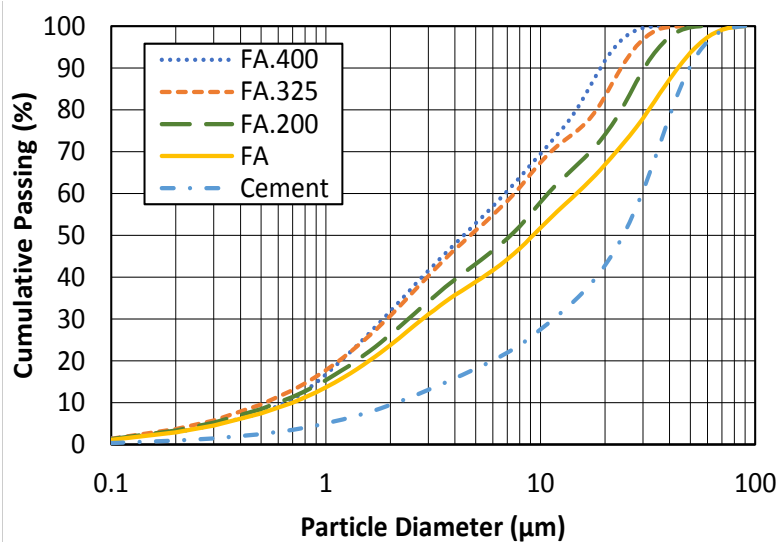

Figure 1. Particle Size Distribution of Cement and Fly Ash Samples.

\section{Superplasticizer Demand}

Fresh mortar with low water to cementitious ratio needs superplasticizer to increase its workability. The addition of superplasticizer in the mixture was performed by spraying the superplasticizer gradually while mixing to achieve the desired workability. The results were confirmed by flow table test to reach the targeted flow diameter of $15 \pm 1 \mathrm{~cm}$ after 25 drops. The need of superplasticizer dosage to achieve the targeted workability or superplasticizer demand varied for different mortar mixtures and its cement replacement ratio. In HVFA mortar, lower superplasticizer demand indicated better fly ash proper- ties in assisting the dispersion of the cementitious material. Fly ash contributes to making higher workability of concrete mixture physically and chemically. The spherical shape of the fly ash acts as ball bearing among the cement particles, while the ionic charge of fly ash particles as measured by its zeta potential could contribute to lowering flocculetion of particles in the cementitious paste [14].

Figure 2 shows the superplasticizer demand for each mixture composition. The mixture designation for sample FA200.60 means fly ash passing sieve No. 200 at $60 \%$ fly ash replacing cement content and so on. Mixture with higher fly ash replacement ratio required lower superplasticizer dosage to achieve the same workability, thus confirming that the fly ash has a positive influence in increasing the workability of the mortar mixture. Fresh HVFA mortar with unclassified fly ash, which did not undergo any sieving process, requires more superplasticizers to achieve the targeted flow diameter than those containing fly ash with smaller particle size. Reduction of superplasticizer demand also means that finer fly ash can be blended into the mortar mixture, dispersing the cement particles to reduce flocculation and to release free water content in the mixture.

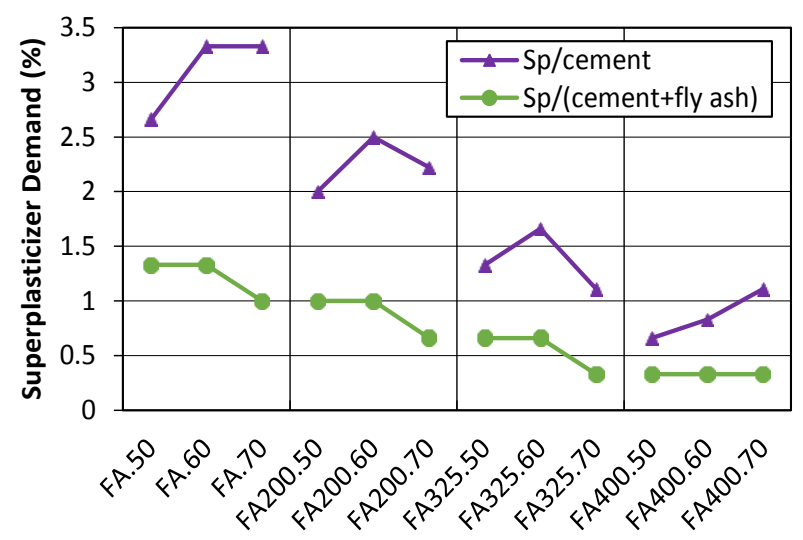

Figure 2. Superplasticizer Demand with Target Flow Table Diameter of $15 \pm 1 \mathrm{~cm}$.

\section{Setting Time}

The setting time of the cementitious paste was tested using the Vicat needle. Figure 3 shows the initial and final setting time of each mixture. It can be seen that in the mixture using unclassified fly ash at 50\% cement replacement (FA.50) has the fastest initial and final setting time, at 220 minutes and 385 minutes, respectively. Higher fly ash content increases the initial and final setting time, due to the reduced cement content and hydration heat in the mixture. Paste with finer fly ash particle in the mixture is shown to have longer initial and final setting time. For instance, HVFA paste containing fly ash passing sieve No 325 at 50\% replacement or 
FA325.50 has an initial setting time of 390 minutes. This could cause some problems with precast concrete production when the initial setting time is excessively delayed. The duration between the initial and final setting time for all mixtures is approximately constant, whereby the average is about 180 minutes. This shows that the delay of initial setting time could be due to the availability of free water in the mixture with the finer particle of fly ash filling the void between cement particles.

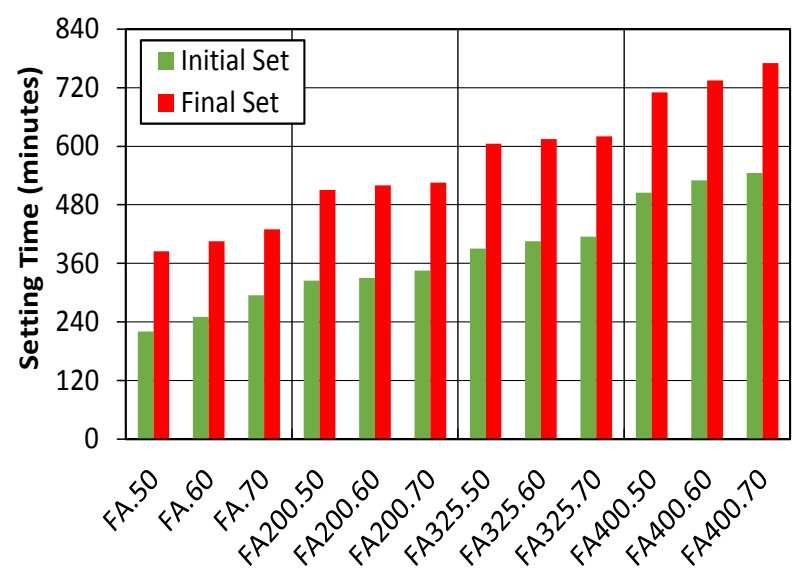

Figure 3. Initial and Final Setting Time of HVFA Paste

\section{Effect of Fly Ash Particle Size Distribution on the Compressive Strength of HVFA Mortar}

Compressive strength tests for cube samples were performed at 7 and 28 days, from the day of mixing. The HVFA mortar was made with fly ash replacement ratio of $50 \%, 60 \%$ and $70 \%$, partially replacing cement, by mass. Fly ash particle size distribution was varied, i.e. unclassified fly ash and fly ash passing sieve No. 200, passing sieve No. 325 , and passing sieve No. 400. Figure 4 shows the compressive strength of each mortar mixture. HVFA mortar with unclassified fly ash mortar can reach $39.6 \mathrm{MPa}$ for $50 \%$ replacement ratio at 28 days. At $60 \%$ and $70 \%$ replacement ratios, the compressive strength was reduced to $33.6 \mathrm{MPa}$ and $27.2 \mathrm{MPa}$, respectively. The reduction rate in compressive strength was high with the increase of cement replacement ratio, about $0.6 \mathrm{MPa}$ per percent increase of fly ash replacement $(\mathrm{MPa} / \% \mathrm{FA})$.

HVFA mortar containing fly ash classified by sieving to reduce the maximum particle size, was showing higher compressive strength at 7 and 28 days, compared to the control HVFA mortar containing unclassified fly ash. The highest compressive strength was achieved for FA325 at 50\% replacement ratio (FA325.50) at $62.8 \mathrm{MPa}$. The specimen of FA400 at 50\% replacement ratio (FA400.50) showed a slightly reduced compressive strength at $57.2 \mathrm{MPa}$. Increasing the fly ash content for mortar FA325 and
FA400 showed a reduced rate of strength reduction. The compressive strength of mortar FA400.50, FA400.60 and FA400.70 are almost the same, showing that increasing the fly ash replacement ratio only slightly reduce the quality of mortar. The strength reduction rates were calculated at 0.62 $\mathrm{MPa} / \% \mathrm{FA}, 0.66 \mathrm{MPa} / \% \mathrm{FA}, 0.42 \mathrm{MPa} / \% \mathrm{FA}$, and 0.16 $\mathrm{MPa} / \% \mathrm{FA}$, for unclassified FA, FA200, FA325, and FA400, respectively, showing that concrete using finer fly ash particle at higher replacement ratio could perform well.

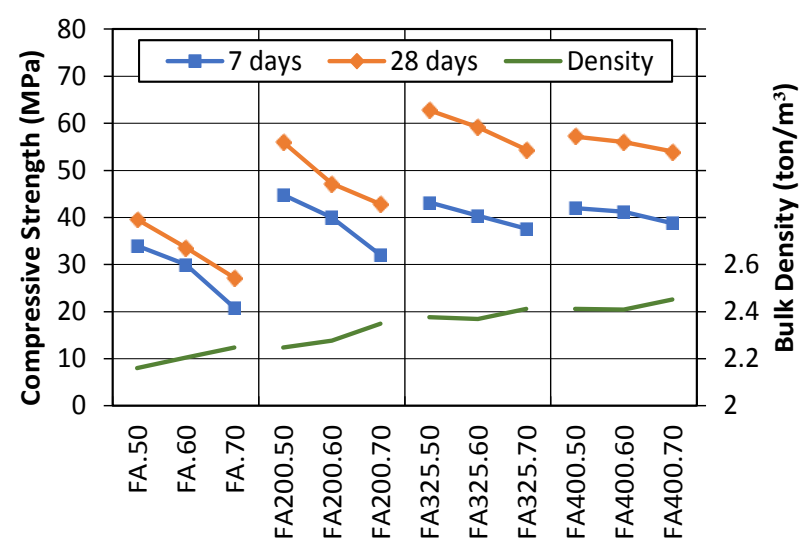

Figure 4. The Compressive Strength and Bulk Density of HVFA Mortar

The bulk density of the mortar samples were also shown in Figure 4. It can be seen that with an increase in fly ash replacement ratio, the bulk density of mortar is higher. Higher density could be due to better workability, with more fly ash particles that act as ball bearing, of the mixture. For HVFA mortar with unclassified fly ash and FA200, the increase of density with the increase of fly ash replacement ratio was not complemented with the increase of compressive strength. However, HVFA mortar containing fly ash with finer particle size distribution showing higher bulk density, most probably due to the increase of the fly ash specific gravity. Fly ash very fine particles can fill voids among cement particles, hence resulting in higher compressive strength. The bulk density of the mortar was increased significantly from around $2.2 \mathrm{t} / \mathrm{m}^{3}$ to $2.4 \mathrm{t} / \mathrm{m}^{3}$ when finer fly ash particles were utilized in the mortar mixture.

Figure 5 shows the strength development of the mortar specimens from 7 to 28 days. The strength increase is an indication of the reactivity of the fly ash in cementitious paste at a later age. The figure clearly shows that the finer fly ash particles can contribute significantly to the strength development of the mortar at age 7 days to 28 days. The highest increase in strength happened at mortar FA325, showing that the optimum fineness for the largest particle size is at $45 \mu \mathrm{m}$. Smaller particle size was 
not necessary to increase the reaction of the cementitious materials. The different strength development rate showed that there was also the influence of the particle size on the pozzolanic reaction in the cementitious phase. The finer particle size of fly ash, up to $45 \mu \mathrm{m}$, could contribute to the development of compressive strength.

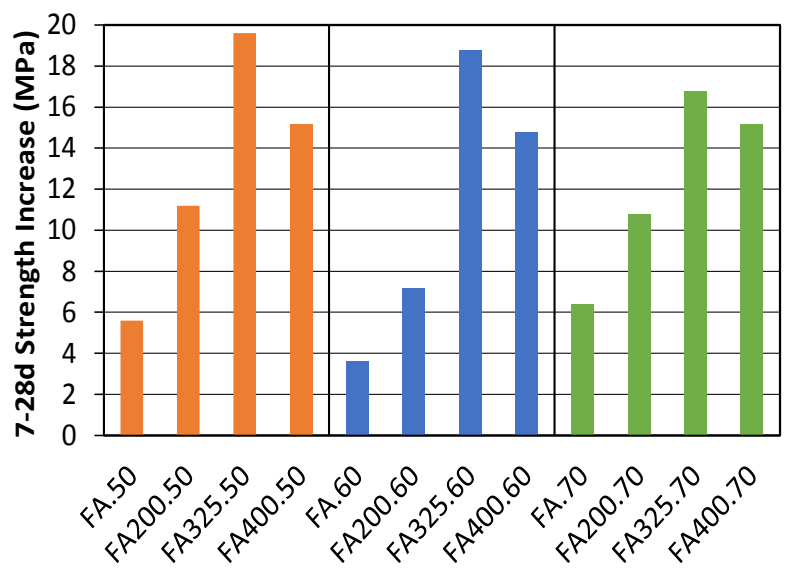

Figure 5. Development of Compressive Strength from 7 to 28 days.

\section{Mortar Microstructure}

The microstructure of HVFA mortar specimens was observed using Scanning Electron Microscope -EDX Carl Zeiss Evo MA10. Figure 6 and Figure 7 show the microstructures observed for FA325 and FA400 with 50\% replacement ratio. The FA325.50 and FA400.50 samples were chosen to be observed due to higher compressive strength found. The figures were taken on the cementitious phases, and it showed the distribution of fly ash in the phase. There were fly ash particles uniformly distributed in the cementitious phases, as it is clearly shown by the spherical shape of the fly ash. Some of the fly ash particles had shown sign of pozzolanic reaction on the surface of the fly ash particle. The pozzolanic reaction is indicated by the occurrence of jagged material or some kind of coating on the otherwise smooth surface of the fly ash. The fly ash particles seem to be uniformly distributed in the phases due to the usage of superplasticizer in the mixture. The fly ash intertwines with the cement matrix in the mixture and shown to be producing a dense microstructure. The particle size measured from the SEM micrograph corresponding with the particle size of the fly ash in the range of few microns.

Adding finer particles would improve the packing of the cementitious material, however, adding finer spherical particles would be better because it could both improving the behavior of fresh concrete and increasing the packing density of the mixture. This effect was also shown by Kwan and Chen [15].

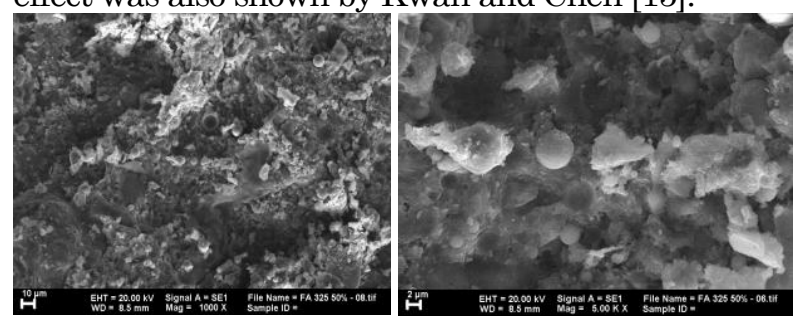

Figure 6. The microstructure of FA325.50 sample enlarged 1000 and 5000 times

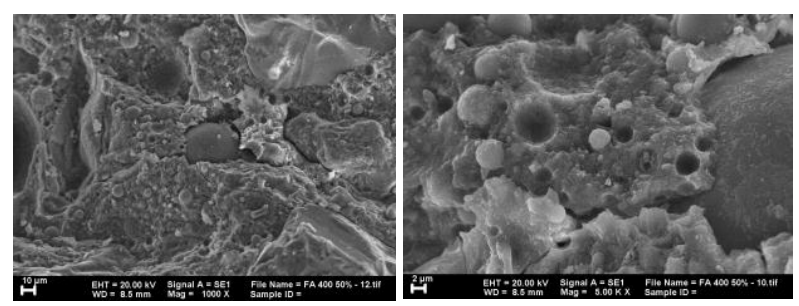

Figure 7. The Microstructure of FA400.50 Sample Enlarged 1000 and 5000 Times

\section{Conclusions}

The experimental study to comprehend the influence of finer fly ash particles in high volume fly ash mortars using high calcium fly ash had been done by classifying fly ash particle distribution using sieve separation. Several conclusions were drawn as follows:

1. The shape of finer fly ash particles remains round after sieve separation, and it can positively contribute to the behavior of fresh and hardened properties of mortar. High volume replacement of cement with finer fly ash produces good quality concrete with high compressive strength.

2. The finer particle size of fly ash improves workability by physical action, which is due to the distribution of smaller fly ash particles in the cement matrix that acts as ball bearing and reducing inter-particles friction. The finer particle of the fly ash also reduces the superplasticizer dosage required to achieve similar workability.

3. Finer fly ash particle in the mortar mixture increases the compressive strength of the mortar, due to several combining factors such as its higher specific gravity of the fly ash particle, the uniformly distributed fly ash particles in the cementitious phase, and the pozzolanic reaction that increases the solidity of the matrix. The optimum increase of strength was found for HVFA mortar with a maximum particle size of fly ash of $45 \mu \mathrm{m}$.

4. The compressive strength of mortar decreases with the increase of fly ash content in HVFA mortar mixture. However, the rate of reduction is reduced when the finer fly ash particle is used.

5. The higher volume of fly ash in the mixture and 
finer particle size of the fly ash causes a longer setting time in the mixture. This effect needs to be addressed when making concrete that required faster setting time.

\section{Acknowledgment}

The authors gratefully acknowledge that the present research is financially supported by The Ministry of Research, Technology and Higher Education of the Republic of Indonesia under the PDUPT Research Grant Scheme (No. SP DIPA-042.06.1.401516/2018).

\section{References}

1. Kumar Mehta, P., High-performance, Highvolume Fly Ash Concrete for Sustainable Development, International Workshop on Sustainable Development and Concrete Technology 3-c (2004). doi:10.15680/IJIRSET.2015.0409047

2. Crouch, L., Hewitt, R., and Byard, B., High Volume Fly Ash Concrete, World of Coal Ash (WOCA), Northern Kentuky, USA (2007).

3. Bentz, D. P. and Ferraris, C. F., Rheology and Setting of High Volume Fly Ash Mixtures, Cement and Concrete Composites, 32, 2010, pp. 265-270.

4. Supit, S. W. M., Shaikh, F. U. A., and Sarker, P. K., Effect of Ultrafine Fly Ash on Mechanical Properties of High Volume Fly Ash Mortar, Construction and Building Materials, 51, 2014, pp. 278-286.

5. Antoni, Satrya, V., and Hardjito, D., Simple Mechanical Beneficiation Method of Coarse Fly Ash with High LOI for Making HVFA Mortar, Civil Engineering Dimension, 17, 2015, pp. 38-43.
6. Antoni, Widianto, A. K., Wiranegara, J. L., and Hardjito, D., Consistency of Fly Ash Quality for Making High Volume Fly Ash Concrete, Jurnal Teknologi, 79, 2017, pp. 13-20.

7. Erdoğdu, K. and Türker, P., Effects of Fly Ash Particle Size on Strength of Portland Cement Fly Ash Mortars, Cement and Concrete Research, 28, 1998, pp. 1217-1222.

8. Chindaprasirt, P., Jaturapitakkul, C., and Sinsiri, T., Effect of Fly Ash Fineness on Microstructure of Blended Cement Paste, Construction and Building Materials, 21, 2007, pp. 1534-1541.

9. Li, G. and Wu, X., Influence of Fly Ash and Its Mean Particle Size on Certain Engineering Properties of Cement Composite Mortars, Cement and Concrete Research, 35, 2005, pp. 1128-1134.

10. Abd Elrahman, M. and Hillemeier, B., Combined Effect of Fine Fly Ash and Packing Density on the Properties of High Performance Concrete: An Experimental Approach, Construction and Building Materials, 58, 2014, pp. 225-233.

11. Bentz, D. P., Hansen, A. S., and Guynn, J. M., Optimization of Cement and Fly Ash Particle Sizes to Produce Sustainable Concretes, Cement and Concrete Composites, 33, 2011, pp. 824-831.

12. ASTM C778-13, Standard Specification for Sand. ASTM International, Pennsylvania, 2013.

13. ASTM C1437-07, Standard Test Method for Flow of Hydraulic Cement Mortar ASTM International, Pennsylvania, 2007.

14. Termkhajornkit, P. and Nawa, T., The Fluidity of Fly Ash-Cement Paste Containing Naphthalene Sulfonate Superplasticizer, Cement and Concrete Research, 34, 2004, pp. 1017-1024.

15. Kwan, A. K. H. and Chen, J. J., Adding Fly Ash Microsphere to Improve Packing Density, Flowability and Strength of Cement Paste, Powder Technology, 234, 2013, pp. 19-25. 